\title{
The Use of Smartphone Applications with Press Coverage during Crisis: A Descriptive Study on a Sample of Sudanese Journalists in the Period from February to June 2016
}

\author{
Elsir Ali Saad Mohamed \\ Correspondence: Elsir Ali Saad Mohamed, Assistant Professor in Mass Communication, Emirates Canadian University \\ College, Umm Al-Quwain, United Arab Emirates.
}

Received: December 28, 2016

Accepted: January 31, 2017

Online Published: March 14, 2017

doi:10.11114/smc.v5i1.2114

URL: https://doi.org/10.11114/smc.v5i1.2114

\begin{abstract}
The present paper tried to throw light on the impact of information technology on press development.

The study adopted a descriptive analytical procedure by using a questionnaire for data collection and the formation of a clearer picture of the evolution attained through implementation of communication means, in particular, the smartphone.

The study concluded that:

- Most of the newspapers possess internal network for the exchange of editorial material between the departments head and the other members of the press staff.

- The implementations of information technology have helped to minimize the steps of gathering press matter.

- There is harmony, between senior and junior staff, in implementing the technical properties of smartphone device. In addition to the fact that smartphone have contributed to the improvement of editorial performance in gathering, preparation, and processing up to the stage of publishing and $\backslash$ or broadcasting.

- It is recommended that there is a need for intensification of the practical training in digital publication. The press editor should be encouraged, by to possess the modern technologies with facilities or free of charge.
\end{abstract}

Keywords: smartphone apps, crisis coverage, Sudanese journalists, information technology

\section{Introduction}

The different eras of human history, since early prehistoric times, have been classified according to their contemporary tools and applications.

Man has been well acquainted with Stone Age, steam era and the era of computer and internet. He has enjoyed the utilization of the discoveries of each era respectively.

At the present time, the most prominent event is the emergence of smartphone and it is importance as means of quick and easy communication. In the last few decades, the human communities practices, in line with the great revolution communication and information technology represented by the computer appliance.

The press was able to attain great benefits from the revolution of information and communication technology through the use of the computer.

In my opinion, the computer has resulted in improving the press performance in its different branches such as radio broadcasting, television, and newspaper.

The present paper tries to throw light on the effect of information technology on press development. The study depended on the analytical and descriptive procedure by preparing a questionnaire for data collection.

\subsection{Research Methodology}

The present study followed the descriptive approach, which is concerned with setting the parameters of the problem, analyzing and interpreting them, The ultimate aim is to reach useful extrapolations (Hijab 2003, p203) Descriptive method was adopted, in the present study for predicting the current status of smartphone application and the extent of its use in printed press coverage, particularly during crisis episodes (Nielsen2012). 


\subsection{Research Hypothesis and Objectives}

The present study is based on two hypotheses:

a- Using smartphone applications in press applications has lead to noticeable advances in the coverage of the crisis. Smartphone and the internet are supported by better mechanisms as compared to other communication tools.

b- There is a gap between the senior and junior journalists. The young press officials are more efficient in using modern communication devices.

The questions of the research problem:

1- What are the prominent press applications provided by smartphone applications?

2- What is the advantage of the smartphone in press environment?

3- What are the motives of using smartphone applications in Sudanese press industry?

\subsection{Research Problem}

As smartphone applications use to increase the quality and acceleration of press coverage during a crisis and helping the journalists creating more credibility news (Kumar, 2011).

The researcher noted that: a few number of journalists concerns resort to using Mobile in the press coverage during times of crisis, such as taking pictures or information sharing (Kumar, 2011).

The current paper focused on the potential of smartphone applications as a new public sphere in new editing, and they will reveal that media features in this applications, using can facilitate democratically desirable outcomes such as political participation.

A journalist working in crisis areas use smartphones because it is the most convenient way to stay connected and accomplish a variety of everyday tasks and they are reasonably priced. The smartphone as a new technology is commonly adopted for maintaining relationships with colleagues (Alamaddin, 2000).

\section{Literature Review}

\subsection{The Concept of Crisis}

The crisis in the language is distress or harsh, the Webster Dictionary defines crisis as a turning point occurs about change for the better or worse, or is the decisive moment or rough time, and a time of great disagreement, confusion, or suffering, also refer to an extremely difficult or dangerous point in a situation, crisis point a moment during a serious illness when there is the possibility of suddenly getting either better or worse, a sudden loss of confidence (merriam-webster.com).

Scientists and researchers define the crisis, it is a cautionary stance involves several risks escalating the most important position and exposure to intense scrutiny of the monitoring by the media (Ashmawy, 2008), or the government, the conflict with the normal work processes as well as exposure positive public image enjoyed by the organization or the responsibility is at risk as well as damage to the results of the work of the organization in any way, among the characteristics of the crisis, surprise, lack of time, the confusion in decision-making, there is an abundance of information, lack of potential tension, the tension and sense of danger (Rwaili: 2011).

In the media perspective, the crisis is defined as "position causes the organization to make the place a widespread negative attention from the media and local and international media, and on the other groups such as consumers and employees, politicians, trade unionists and legislatures (Eslim, 2007 \& Regester, 2002).

The media perspective in crisis and disaster management "has a growing importance as is a key component of an integrated mix of various sciences in the study of crises components, Is a mix which assumes that every crisis involving complex and intertwined relationships of individual and collective things are internal and external. (Mekkawi, 2005).

The crisis may be sudden and unexpected, and confusing, so that creates a state of tension and anxiety, and uncertainty in the available alternatives, especially in the lack of information, "it also occur more rapidly, thus losing parties to the crisis the ability to control the situation, especially in distress time available to deal with the crisis and its repercussions, also, serious threats, so sometimes lead to material losses and immense human " (Rogester \& Larkin 2002)

The mass communication operates in a time of crisis to "demystify the crisis, in order to prevent rumors and protect the image and reputation of the organization, and to deal intelligently with the media to limit their drawbacks, and satisfy their need for information during the crisis, and in a way to ensure not to exacerbate, and the supply of media all the facts of the situation and developments first hand." (Shaaban:2005). 
That the media in a crisis situation "is the double-edged sword, they either contribute to containing the crisis, and to avoid the negative effects arising from them, and support the position of the institution, and it causes a crisis of the institution of the reality of the media coverage of the crisis, which may cause a crisis of credibility in the organization, and raise public opinion against the position, which offers services to the public." (Ashmawi: 2008).

Degrees of public adoption vary on the media as a source of information in the event of a crisis, this relationship is clearly growing under conditions of social stability and social changes and the threat of conflict and its different forms, particularly in the case of security crises. Resort individuals in this case to the media in an attempt to create a constant sheen of events and to find the proper interpretation. (Bait Almal:2011).

Press coverage is defined as "the process of getting the most amount of information on a specific event through the adoption of a journalist in charge of the delegate of covering up its sources, and methods to get the facts and information on the issue of interest to a certain segment of people, or of interest to most people for any reason and displayed in a clear and obvious.( Rubaie:2012).

The media should be a performance in times of crisis on the highly important and sensitive so that the informational messages directed to the public during the security crisis intervention and its development as a key element in the interactions of the crisis positively and negatively. (Salah: 2012)

\subsection{The Concept of the Information Technology Evolution}

Information technology is the application of computers and internet to store, study, retrieve, transmit, and manipulate data, or information, often in the context of a business or other enterprise. Information Technology is considered a subset of information and communications technology (ICT) (Shaaban, 2005).

The term is commonly used as a synonym for computers and computer networks, but it also encompasses other information distribution technologies such as television and telephones. Several industries are associated with information technology, including computer hardware, software, electronics, semiconductors, the internet, telecom equipment, engineering, and healthcare, e-commerce, and computer services (Wikipedia).

The development, which provides news of modern communication technologies has enabled him to handle, writing for the press, and it appeared as an extension of the developments brought about by information technology in the press and edit the news and extended to include news-makers and editors (mmu.edu.my).

Press editing is a science and an art of transforming events, idea's and experiences and humanitarian issues, article can be understood when the various categories of recipients, which is the general theory of journalism is based, and the theory of journalistic genres, that define journalistic types and areas of use, and the tasks and functions that can be completed, and the stages of the process of creativity.

The editorial is a reflection of the potential of an intellectual, cultural and professional journalist.

\subsection{The Features of the Modern Means of Communication}

Significant changes to the editor of the work, it has emerged as the electronic news term which is used in the preparation of the technical media article instead of the old media (Fadly, 2005).

Technical development has contributed to the emergence of new technologies and tools to serve the journalistic work, the helps journalists to create content professionally, the easily superior (lamya, 2014).

Press editing by using modern technical means intended to replace paper-based tools used by the editor technology tools achieve a higher level of accuracy during the writing process, especially if you use a subsidized potential linguistic correction word processing program, or monitoring of language and correct errors, in addition to providing a greater degree of speed when the desire to make adjustments by deletion or addition, or transfer the particles that make up the press material.

Modern means of communication and information characterized by many features including multimedia, interaction and participation, empowerment, networking and the ability to control exposure conditions, speed and immediate and continuous updating, personalization, - open borders, flexibility, archiving, saving time, effort and money.

\subsection{Media Features of Information Technologies}

The most prominent media features offered by information technologies, communication services, mailing lists, newsgroups or discussion groups, to participate in the vote or opinion polls, declined to comment on the news, the dialogue with the different personalities.

In the broadcast and publishing services, television broadcasting, online radio, re-deployment of the newspaper as a PDF or Flash, a subscription service in the printed newspaper (Gheitas, 2009), Technology simultaneous publication Simple RSS (Really Simple Syndication), podcasts Podcast service. 
On the side of search services and downloading files, the search service, search the Archive Service, and the participation of other news.

\subsection{The Smartphone}

Is the term given to a class of modern mobile phones that use the sophisticated operating system, most of the touch screen is used as an interface user is running mobile applications?

If no agreement is reached between the manufacturers of mobiles on a common definition of the smartphone, some of them considered a smartphone is a phone that offers the advantages of surfing the Internet and synchronize e-mail and open MS Office files, and has a full keyboard QWERTY (Alakbawi,2010), although there was no agreement between the manufacturers of mobile phones on a common definition of the smartphone but the common definition and most widely accepted today that mobile phone that works on one of the following operating systems: Windows Phone, or, Linux, or their derivatives, is considered running Apple OS (iPhone) and Google's Android and Nokia's system of elaborate systems for Linux, it's referred to as Mobiles operating on one of these systems Phones smart because they often are where all the previous conditions are met (Wikipedia).

Smartphones are no different from laptops, personal computers or any other device in anything, each smart devices consist of a two-part complementary to each other are: the Hardware, is a physicist part that possible to the touch, the Software is part programmatic operator of the device (operating system) (Shikhani, 2010), who leads the Hardware such as Windows and Linux, without operating system device cannot be work (Sadiq, 2003).

Operating systems began to evolve at the hands of Nokia, where we drove Symbian OS system and was the first advanced operating system, enough to meet the simple and some complex needs, in the same time period was Samsung's own OS system.

Smartphone differs from the traditional phone in that it provides a number of functions and advanced computing capabilities and advanced communication along with other traditional phone functions.(Aljazeera net:2014).

The integration of the first smartphones It was between traditional phone capabilities and benefits of other popular consumer devices such as PDA and media player and digital camera, and GPS positioning system (GPS).

The current smartphones, it supports additional features more advanced, such as resistance touchscreens to scratches, compact cameras, and high-resolution imaging, we have begun to see smartphones have cameras precisely 16 megapixels, twenty-megapixels, and some arrived in the matter to an unprecedented accuracy of 41 megapixels, smartphone features as well as strong with equipment such as dual-core processors and the Quartet cores and eight cores, as well as smartphone includes a special graphics processors enables operation of three-dimensional games, and random access memory (RAM) is sufficient and adequate storage space.

\subsection{Employ Phone Applications in Coverage during Crises}

As technological developments brought about a coup in the press and the news editor has the same thing with editors and Newsmakers there has become the citizen journalist, a journalist who can handle and writing in the newspaper using electronic means, the introduction of electronic editing system as an alternative to manual editing to the editor printed the paperwork from several angles such specificity typography angle to Puntland title according to the degree of importance of press material and the angle of the relationship between writers, editors and reporters outside the headquarters of the newspaper has affected.

\subsection{Models of Smart Applications}

1. Story Maker, which is an open source application run on the Android operating system, the application is primarily intended for journalists and citizen journalists, it was developed by a group interested in journalism and international organizations such as the Organization unlimited Free Press, and The Guardian Project and others.

The application allows users to do editing and filming and production of digital stories, relying entirely on this application without the need for any tools beyond him, and published live through it.

The application takes the slogan "Learning, Make, participated" to express his goal and function. The application is based on two parts, the first is a special lessons part, which you can find many diverse and renewable states and classified according to different areas, where you can choose between lessons in journalism, photography and editing, digital audio and security, and to download any of the lessons you want easily, The second part is the part of the relevant industry news reporting the story, which lets you program a few simple and easy steps to producing a digital story, you'll find a place to put the title, another to choose a mediator type you want, whether text, video, image or audio clip, the application also lets you model that can 
be used to produce digital story and add what you wants from the text, images and other and add an explanation of the story and many other possibilities such as the combination of sound and images, and other.

2. Telegram and an application of text-messaging supports strict confidentiality, security, and is characterized by several features, including the possibility of working groups of up to a thousand members and the channels establishment of news websites an unlimited number of members and send voice messages are encrypted and cannot any third party shall have access to its content, as well as the possibility of the destruction of messages self after a period specified by the user.

3. Soma and an application of text-messaging, voice, and video conversations are also characterized by secrecy and safety were not stored conversations on servers, and is cleared all the messages that have not been received from the second party after a week and a technical advantage of the purity of the sound and picture quality and the possibility of working groups for voice conversations.

4. phone It is also the application of text-messaging and audio and video and is completely safe and is distinct from the rest of the applications its failure to introduce a phone number, but a personal account is similar to email and more like Skype.

\subsection{Technical Effect on the Press Editors in Sudan}

To see how the Sudanese journalist benefited from applications provided by information technology and its impact on the editorial process, a questionnaire was designed and distributed to a sample consisting of 75 journalists via e-mail and Facebook's response was $86 \%$, the Response rate in the first ten minutes about $48 \%$ of the total sample.

Table (1). Sex and Percentages of the Sample

\begin{tabular}{lll}
\hline Categories & Frequencies & Percentage \\
\hline Male & 51 & $78 \%$ \\
Female & 14 & $22 \%$ \\
& 65 & $100 \%$
\end{tabular}

Ages ranged from 15 years to 25 years the proportion of $7 \% .26$ to 35 years the proportion of $33 \%$, $43 \% 36-45 \mathrm{snh}$, where the majority of the $15-45$ age group by $84 \%$ and the age group between $46-65$ years amounted to $17 \%$.

Table (2). The age groups

\begin{tabular}{lll}
\hline Categories & Frequencies & Percentage \\
\hline $25-15$ & 5 & $7 \%$ \\
$35-26$ & 21 & $33 \%$ \\
$45-36$ & 28 & $43 \%$ \\
$55-46$ & 5 & $7 \%$ \\
$65-56$ & 7 & $10 \%$ \\
& 65 & $100 \%$
\end{tabular}

Table (3) pointed that the $61 \%$ of the sample of bachelor campaign while the campaign degrees above the BSc (Diploma, Masters, and Ph.D.) were up 29\%.

Table (3). Educational level of the sample

\begin{tabular}{lll}
\hline Categories & Frequencies & Percentage \\
\hline Schools & 7 & $10 \%$ \\
University & 40 & $61 \%$ \\
Post Graduate & 19 & $29 \%$ \\
& 65 & $100 \%$
\end{tabular}

Table (4) shows that the sample varied specializations between media, languages, information technology, international relations, engineering, economics, and sociology at rates $44 \% 0.11 \% 0.6 \% 0.6 \% 0.6 \% 0.11 \% 0.16 \%$, respectively . 
Table (4). Number and \% of academic disciplines of the sample

\begin{tabular}{lll}
\hline Categories & Frequencies & Percentage \\
\hline Media & 29 & $44 \%$ \\
Language & 7 & $11 \%$ \\
Computer \& IT & 4 & $6 \%$ \\
International Relations & 4 & $6 \%$ \\
Sociology & 7 & $11 \%$ \\
Economy & 10 & $16 \%$ \\
& 65 & $100 \%$
\end{tabular}

Table (5) respondents classified by function within the newspaper where he participated editors and managers editor and columnist of $17 \%$ for each category, heads of departments by $22 \%$, the editors of $27 \%$.

Table (5). Sample positions inside the institution

\begin{tabular}{lll}
\hline Categories & Frequencies & Percentage \\
\hline Editor-in chief & 11 & $17 \%$ \\
Managing Editor & 11 & $17 \%$ \\
Columnist & 11 & $17 \%$ \\
Head Section & 14 & $22 \%$ \\
Editor & 18 & $27 \%$ \\
& 65 & $100 \%$ \\
\hline
\end{tabular}

The questionnaire shows the sample is subjected to communication applications and using them in the development of journalism as explained $77 \%$ of the sample that they have the mobile devices supporting Android applications, The sample of $100 \%$ have e-mail, $50 \%$ of the sample (s) email more than once during the day, $72 \%$ s mail via mobile phone, admitted $89 \%$ of the sample size of the existence of the evolution of the editorial performance due to technical, $90 \%$ of their printing press their material themselves and choose the appropriate images from the archives or the Internet as well as the delivery of materials through an intermediary technical (Flash or send internal network to the newspaper ) $0.50 \%$ of respondents pointed to reduce the presence of newspapers to print on the computer technician $0.78 \%$ share their writings through social networking sites and $22 \%$ equally between personal blogs and codes offered by newspapers.

Table (6). Possession of communication technology in the sample (\%)

\begin{tabular}{llllll}
\hline Categories & Yes & \multicolumn{3}{l}{ No } \\
\cline { 2 - 6 } & Freq. & $\%$ & Freq. & \% \\
Owned a device that supports Android & 50 & $77 \%$ & 15 & $23 \%$ \\
I have an email & 65 & $100 \%$ & 0 & 0 \\
access e-mail via phone & 47 & $72 \%$ & 18 & $28 \%$ \\
Use the phone in the editing & 58 & $89 \%$ & 7 & $11 \%$ \\
Keep an archive in a telephone & 59 & $90 \%$ & 7 & $11 \%$ \\
Type articles and send it & 33 & $50 \%$ & 33 & $50 \%$ \\
No character's in the newspaper & 51 & $78 \%$ & 14 & $22 \%$ \\
\hline
\end{tabular}

\section{Results}

Evident from the data that came out of questionnaire:

1. A large proportion of the newspapers has a private internal network is the exchange of materials between the editor and head of the department, and the department head and editorial director, and the managing editor and editorial secretary and two to the editor.

2. Applications provided by information technology, which summed up the steps and helped to improve the content. 
3. There is a balance in the use of technology applications in smartphones between the young journalists and the elderly.

4. Respondents said that there is a negative impact in the field coverage of the events of the adoption of the editor on the network colleagues from other newspapers.

5. Smartphones have contributed to the development of editorial performance regarding the collection of information and communication resources and the preparation and processing of information until the stage of publishing or broadcasting.

6. There is a positive correlation between the research specimens and the use and applications of the smartphone in press performance, of even during crisis times (Table 6).

7. Also, table (6) shows a positive correlation between the different classes, in the researched specimens, and their interest in following the smartphone application stages.

8. There is a positive correlation between the response of pioneer press generation and smartphone applications and this is reflected in their quick response to the questionnaire. This leads us to agree that advances in technology are always accompanied by increased interest in all press levels. That might be due to the curiosity of press officials for testing and applying any new technique.

\section{Recommendations}

1. There is a need for practical training intensification in the digital publication field.

2. Intensification of training courses in the fields of publishing applications uses the digital press. Encourage the editor to possess modern applications with facilities or free grants from corporations, to improve their performance.

3. Encourage further research and studies to assess and evaluate the impact of technology and its impact on press performance.

4. With the increase in Internet service speed and availability of more than the means by which the average user access to data, where a lot of things that go into everyday uses of the human being become connected to the Internet, and the success of innovations and devices in the future "will depend on its ability to disappearance of our lives in the sense that the ideal situation is not to hold any hardware at all, with the ability to harness and manage decryption code filtering and data analysis.

\section{References}

Alakbawi, B. (2010). Electronic media and its website, the first edition (Jeddah: Khawarizmi Scientific for Publishing and Distribution.

Alamaddin, M. (2000). Press in an era of basics information and innovations, without edition (Cairo: Al-Ahram Press)

Aljazeera Net: www.aljazeera.net/news/scienceandtechnology/2014/5/18/-

Ashmawy, M. A. W. H. (2008). Press coverage of the crimes of revenge between my family Azzam and vegetables, and my family and Abdel Halim Activities In the role of newspapers in Crisis Management: A Case Study of a crime of revenge. Knowledge / Alexandria. Facility.

Bait, A., \& Hamza, A. (2011). Media, and security crisis, media software security between reality and aspirations, Naif Arab University for Security Sciences.

Eslim, W. S. M. (2007). Attributes Crisis in the Palestinian government institutions - a field study on the Finance Ministry in Gaza Master, the Islamic University -Gaza.

Fadly, M. (2005). E reality and the future of the press, without edition (Cairo, without a publishing house).

Gheitas, G. (2009). editing the backbone of the future Hall information edit, an article published, Al-Ahram newspaper site on the web http://digital.ahram.org.eg systems, Date of publication.

Hijab, M. M. (2003). Media Glossary, Dar Al-Fajer for Publishing, Cairo.

Kumar, R. (2011). Research Methodology A Step-by-Step, 3rd Ed. SAGE Publications Inc, London.

Lamya, J. (2014). Electronic Journalism Revolution in the beginning of the end of its significance for the media classic, published studies, the website of the Algerian Radio http://www.radioalgerie.dz/ar/.

Mekkawi, E. H. (2005). Media and Crisis, the Lebanese house of the Egyptian. merriam-webster.com

Multimedia applications Services, platforms, and technologies, http://www.mmu.edu.my 
Nielsen, R. K. (2012). Ten Years that Shook the Media World Big Questions and Big Trends in International Media Developments, Reuters Institute for the study of journalism.

Regester, M., \& Larkin, J. (2002). Risk Issues \& crisis Management A casebook of Best Practice. (2nd Ed.), London, Kogan page, PP55

Rubaie, Z. H. (2012). Press coverage of the crisis, search unsheathed from his doctoral thesis, researcher Media Magazine Issue.

Rwaili, A. B. H. (2011). Crisis Management, private Saudi Food and Drug foreign ministry scientific episode, Naif Arab University for Security Sciences.

Sadiq, A. M. (2003). press the Internet and electronic publishing, the first edition (Abu Dhabi Al Dhafra to print.

Salah, M. A. M. (2012). New media, and managing security crisis, Scientific Forum - security media and its role in crisis management, Amman, Jordan.

Shaaban, H. (2005). Security media, crisis management and disaster, Cairo.

Shikhani, S. (2010). New Media in the era of information, research publication, Journal of the University of Damascus, Volume 26.

Wikipedia: https://en.wikipedia.org/wiki/Information_technology.

\section{Copyrights}

Copyright for this article is retained by the author(s), with first publication rights granted to the journal.

This is an open-access article distributed under the terms and conditions of the Creative Commons Attribution license which permits unrestricted use, distribution, and reproduction in any medium, provided the original work is properly cited. 